\title{
SMALl SAMPLE Properties OF MAXIMUM LIKELIHOOD VERSUS GENERALIZED METHOD OF MOMENTS BASED TESTS FOR SPATIALLY AUTOCORRELATED ERRORS
}

\author{
PETER EGGER \\ MARIO LARCH \\ MICHAEL PFAFFERMAYR \\ JANETTE WALDE \\ CESIFO WORKING PAPER NO. 1558 \\ CATEGORY 10: EMPIRICAL AND THEORETICAL METHODS \\ OCTOBER 2005 \\ An electronic version of the paper may be downloaded \\ - from the SSRN website: \\ www.SSRN.com \\ - from the CESifo website: \\ www.CESifo-group.de
}




\title{
SMALl SAMPLE PROPERTIES OF MAXIMUM LIKELIHOOD VERSUS GENERALIZED METHOD OF MOMENTS BASED TESTS FOR SPATIALLY AUTOCORRELATED ERRORS
}

\begin{abstract}
This paper undertakes a Monte Carlo study to compare MLE-based and GMM-based tests regarding the spatial autocorrelation coefficient of the error term in a Cliff and Ord type model. The main finding is that a Wald-test based on GMM estimation as derived by Kelejian and Prucha (2005a) performs surprisingly well. Our Monte Carlo study indicates that the GMM Wald-test is correctly sized even in small samples and exhibits the same power as their MLE-based counterparts. Since GMM estimates are much easier to calculate, the GMM Wald-test is recommended for applied researches.
\end{abstract}

JEL Code: C12, C21, R10.

Keywords: spatial autocorrelation, hypothesis tests, Monte Carlo studies, maximum likelihood estimation, generalized method of moments.

Peter Egger

Ifo Institute for Economic Research at the University of Munich

Poschingerstr. 5

81670 Munich

Germany

egger@ifo.de

Michael Pfaffermayr

University of Innsbruck

Faculty of Economics and Statistics

Universitätsstr. 15

6020 Innsbruck

Austria

Michael.Pfaffermayr@uibk.ac.at
Mario Larch

Ifo Institute for Economic Research at the University of Munich

Poschingerstr. 5

81670 Munich

Germany

larch@ifo.de

Janette Walde

University of Innsbruck

Faculty of Economics and Statistics

Universitätsstr. 15

6020 Innsbruck

Austria

Janette.Walde@uibk.ac.at

The authors gratefully acknowledge numerous helpful comments by Ingmar Prucha. 


\section{Introduction}

The recent literature on the estimation of processes with spatially autocorrelated errors distinguishes between two estimation principles: maximum likelihood estimation (henceforth MLE; Cliff and Ord, 1981; Anselin, 1988; Lee, 2004) and estimation by the generalized method of moments (henceforth GMM; Conley, 1999; Kelejian and Prucha, 1999, 2002). Whereas MLE relies on normally distributed errors, GMM is flexible with regard to the distribution of the innovations. However, this advantage of GMM comes at the expense of an efficiency loss as compared to MLE.

This paper focuses on the small sample properties of Wald, Likelihood Ratio (LR), and Lagrange Multiplier (LM) tests for processes with spatial autoregressive residuals (SAR). Specifically, we provide a comparison of MLE- and GMM-based tests. Whereas MLE naturally obtains variance-covariance estimates of all parameters including the SAR coefficient, this does not hold true for all GMM-type models. For instance, Kelejian and Prucha (1999) suggest a two-step procedure to estimate the SAR coefficient that does not provide its standard error. Similarly, Conley (1999) proposes a heteroskedasticity and autocorrelation consistent (HAC) non-parametric estimator of the variance-covariance matrix that excludes the SAR coefficient. Kelejian and Prucha (2005b) suggest a HAC-estimator of the variance-covariance matrix of the regression parameters that excludes the SAR parameter as well. ${ }^{1}$ In a recent paper, Kelejian and Prucha (2005a) derive the asymptotic distribution of the GMM-based SAR parameter under a set of general assumptions allowing for heteroskedasticity of the error term. In particular, they obtain a consistent estimate of the variance of the SAR parameter upon which a test can be based.

So far, evidence on the relative performance of MLE- versus GMM-based tests for SAR processes seems not to be available. ${ }^{2}$ It is this paper's objective to investigate

\footnotetext{
${ }^{1}$ Conley's (1999) approach works under a different set of assumptions than that one of Kelejian and Prucha (2005b). See Lee (2001) for a related approach.

${ }^{2}$ Burridge (1980), Anselin and Rey (1991), Kelejian and Robinson (1992), Kelejian and Robinson (1993), Anselin, Bera, Florax, and Yoon (1996), Anselin and Florax (1995), Kelejian and Robinson (1997), Anselin (2001), Kelejian and Prucha (2001), Anselin and Moreno (2003), Kelejian and Prucha (2005a) are excellent contributions on testing for spatial correlation, and by no means this list is exhaustive. However, these papers partly do not focus on SAR but on different spatial processes (e.g., Kelejian and Robinson, 1992, Anselin and Moreno, 2003), partly they consider
} 
the size and power of MLE-based versus GMM-based tests against spatially autocorrelated residuals in small samples by setting up an extensive Monte Carlo study. Our primary goal is to derive results that facilitate the choice among available tests for applied researchers.

The next section lays out the data generating process and the Wald-, LR-, and LMtype tests based on MLE and the GMM-based Wald-test. Section 3 describes the design of our Monte Carlo study, whereas section 4 summarizes our main findings with regard to the size and power of the tests. The last section concludes with a summary of our main findings.

\section{The Data-Generating Process}

Ord (1975) type models with spatially autocorrelated residuals can be formulated in the following way: ${ }^{3}$

$$
\begin{aligned}
\boldsymbol{y} & =\boldsymbol{X} \boldsymbol{\beta}+\boldsymbol{u}, \\
\boldsymbol{u} & =\rho \boldsymbol{W} \boldsymbol{u}+\boldsymbol{\varepsilon},
\end{aligned}
$$

where $\boldsymbol{y}$ is an $n \times 1$ vector of observations on the dependent variable, with $n$ denoting sample size. $\boldsymbol{X}$ is an $n \times k$ matrix of non-stochastic explanatory variables, where $\lim _{n \rightarrow \infty} \frac{1}{n} \boldsymbol{X}^{\prime} \boldsymbol{X}$ exists and is non-singular. $\boldsymbol{\beta}$ is the $k \times 1$ vector of parameters, and $\boldsymbol{u}$ is an $n \times 1$ vector of spatially autocorrelated disturbances. $\boldsymbol{W}$ denotes a rownormalized spatial weights matrix of size $n, \rho$ is the SAR parameter with $|\rho|<1$.

only a single test principle (e.g., Kelejian and Robinson, 1992, Anselin, 2001, Kelejian and Prucha, 2001), and partly they focus only on MLE-based tests (e.g., Burridge, 1980, Anselin and Rey, 1991, Anselin, Bera, Florax, and Yoon, 1996, Anselin, 2001) or only on GMM-based estimates (e.g., Kelejian and Robinson, 1993, Kelejian and Prucha, 2005a). Hence, the aim of previous research was not to provide an analysis of a large class of tests against SAR based on MLE versus GMM.

${ }^{3}$ There is an extensive line of research on the estimation and testing of models with endogenous spatial lags (Anselin, 1988, Lee, 2003, Kelejian and Prucha, 1999, Pinkse, Slade, and Brett, 2002, Saavedra, 2003). The GMM-type literature focuses on instrumental variable estimation and the choice of optimal instruments. However, that branch of the literature does not focus on tests against SAR. 
Hence, $(\boldsymbol{I}-\rho \boldsymbol{W})^{-1}$ is non-singular and uniformly bounded in absolute value. $\boldsymbol{\varepsilon}$ is an $n \times 1$ vector of errors, $\varepsilon_{i} \sim i . i . d .\left(0, \sigma^{2}\right)$, with finite second and fourth moments. A comprehensive set of assumptions underlying GMM-estimation is given in Kelejian and Prucha (1999, 2005a).

\section{Tests on Spatially Autocorrelated Errors}

\subsection{Estimators}

For estimation and testing, we consider two different principles: MLE and GMMestimation. MLE assumes normally distributed errors, and the log-likelihood function for the data generating process outlined above is given by (see Anselin, 1988)

$\ln L=-\frac{n}{2} \ln (2 \pi)-\frac{n}{2} \ln \left(\sigma^{2}\right)-\frac{1}{2 \sigma^{2}}(\boldsymbol{y}-\boldsymbol{X} \boldsymbol{\beta})^{\prime}(\boldsymbol{I}-\rho \boldsymbol{W})^{\prime}(\boldsymbol{I}-\rho \boldsymbol{W})(\boldsymbol{y}-\boldsymbol{X} \boldsymbol{\beta})+\ln |\boldsymbol{I}-\rho \boldsymbol{W}|$.

This log-likelihood function can be concentrated to a non-linear function of the spatial parameter $\rho$ only. Hence, optimization can be accomplished by univariate non-linear techniques based on the Nelder-Mead Simplex method (see Lagarias, Reeds, Wright, and Wright, 1998). Standard errors are derived from the inverse of the information matrix (see Anselin, 1988, for details).

In contrast, GMM does not rely on distributional assumptions and the estimators are easy to calculate (see Kelejian and Prucha, 1999, 2005b). The moment conditions related to $\rho$ and $\sigma^{2}$ are given by:

$$
\begin{aligned}
& E\left[\frac{1}{n} \varepsilon^{\prime} \varepsilon\right]=\sigma^{2} \\
& E\left[\frac{1}{n} \bar{\varepsilon}^{\prime} \bar{\varepsilon}\right]=\sigma^{2} \frac{1}{n} \operatorname{tr}\left(\boldsymbol{W} \boldsymbol{W}^{\prime}\right) \\
& E\left[\frac{1}{n} \bar{\varepsilon}^{\prime} \varepsilon\right]=0
\end{aligned}
$$

After substituting the first moment condition into the second one and using the notation $\overline{\boldsymbol{u}}=\boldsymbol{W} \boldsymbol{u}$ and $\overline{\overline{\boldsymbol{u}}}=\boldsymbol{W}^{2} \boldsymbol{u}$, the two moment conditions for $\rho$ can be written 
as follows:

$$
\begin{aligned}
E\left[\frac{1}{n}(\overline{\boldsymbol{u}}-\rho \overline{\overline{\boldsymbol{u}}})^{\prime}(\overline{\boldsymbol{u}}-\rho \overline{\overline{\boldsymbol{u}}})\right] & =E\left[\frac{1}{n}(\boldsymbol{u}-\rho \overline{\boldsymbol{u}})^{\prime}(\boldsymbol{u}-\rho \overline{\boldsymbol{u}})\right] \frac{\operatorname{tr}\left(\boldsymbol{W}^{\prime} \boldsymbol{W}\right)}{n} \\
E\left[\frac{1}{n}(\overline{\boldsymbol{u}}-\rho \overline{\overline{\boldsymbol{u}}})^{\prime}(\boldsymbol{u}-\rho \overline{\boldsymbol{u}})\right] & =0
\end{aligned}
$$

A consistent estimate of the residuals $\boldsymbol{u}$ is obtained by ordinary least squares, ignoring the spatial correlation of the error term. These residuals are plugged into the above moment conditions to obtain a consistent estimate of $\rho$. For the subsequent exposition, it is useful to write the above two moment conditions in vector form as $\tilde{\boldsymbol{\Gamma}}\left(\begin{array}{c}\rho \\ \rho^{2}\end{array}\right)=\tilde{\boldsymbol{\gamma}}$. The estimate of the spatial correlation coefficient $\tilde{\rho}$ is defined as $\tilde{\rho}=\arg \min \left[\left(\tilde{\boldsymbol{\gamma}}-\tilde{\Gamma}\left(\begin{array}{c}\rho \\ \rho^{2}\end{array}\right)\right)^{\prime} \tilde{\Upsilon}^{-1}\left(\tilde{\boldsymbol{\gamma}}-\tilde{\Gamma}\left(\begin{array}{c}\rho \\ \rho^{2}\end{array}\right)\right)\right]$

where $\widetilde{\Upsilon}$ is a $2 \times 2$ symmetric positive semidefinite (moments) weighting matrix. Kelejian and Prucha (2005a) recently derived the limit distribution of $\widetilde{\rho}$ as well as a consistent parametric estimate of its variance:

$\sqrt{ } n(\widetilde{\rho}-\rho) \sim N\left(0, \boldsymbol{\Omega}_{\tilde{\rho}}\right)$,

They showed that $\boldsymbol{\Omega}_{\widetilde{\rho}}$ can be consistently estimated by:

$\widetilde{\Omega}_{\widetilde{\rho}}=(\widetilde{\boldsymbol{J}} \widetilde{\Upsilon} \widetilde{\boldsymbol{J}})^{-1} \widetilde{\boldsymbol{J}} \widetilde{\Upsilon} \widetilde{\boldsymbol{\Psi}} \widetilde{\boldsymbol{J}}(\widetilde{\boldsymbol{J}} \widetilde{\Upsilon} \widetilde{\boldsymbol{J}})^{-1}$,

where

$$
\begin{aligned}
& \widetilde{\boldsymbol{J}}=\widetilde{\boldsymbol{\Gamma}}\left(\begin{array}{c}
1 \\
2 \widetilde{\rho}
\end{array}\right), \\
& \widetilde{\boldsymbol{\Psi}}=\left[\widetilde{\psi}_{r s}\right]_{r, s=1,2}, \widetilde{\psi}_{r s}=\widetilde{\sigma}^{4}(2 n)^{-1} \operatorname{tr}\left[\left(\boldsymbol{A}_{r}+\boldsymbol{A}_{r}^{\prime}\right)\left(\boldsymbol{A}_{s}+\boldsymbol{A}_{s}^{\prime}\right)\right], \\
& \boldsymbol{A}_{1}=\boldsymbol{W}^{\prime} \boldsymbol{W}-\operatorname{diag}_{i=1}^{n}\left(n^{-1} \operatorname{tr}\left(\boldsymbol{W}^{\prime} \boldsymbol{W}\right)\right), \text { and } \\
& \boldsymbol{A}_{2}=\boldsymbol{W},
\end{aligned}
$$

For one variant of the test, we use $\widetilde{\boldsymbol{\Upsilon}}=\boldsymbol{I}_{2}$. The Wald-test based on this estimate is referred to as 'Wald GMM'. Kelejian and Prucha (2005a) also showed that inserting a consistent estimate $\widetilde{\boldsymbol{\Psi}}^{-1}$ for $\widetilde{\boldsymbol{\Upsilon}}$ leads to the efficient GMM estimator of $\rho$. The Wald-test based on the estimate with the efficient GMM estimator is referred to as 'Wald GMM eff.'. 


\subsection{Test Statistics for $\rho=0$}

The most common test for $H_{0}: \rho=0$ is the Moran $I$ test statistic, which tests for the lack of spatial correlation in the residuals against an unspecified alternative. Under the present assumptions, the Moran $I$ test statistic is equivalent to an MLE-based LM-test (see Kelejian and Prucha, 2001).

In the specified model with SAR-errors, one is able to test directly for $\rho=0$ against $\rho \neq 0$. For this, we rely on the three familiar asymptotic testing principles, i.e., the Wald-test, the LR-test, and the LM-test. First, we calculate the following statistics regarding the null hypothesis $H_{0}: \rho=0$ by means of the MLE approach:

$$
\begin{aligned}
W_{M L} & =\frac{\hat{\rho}}{\hat{\sigma}_{\rho}}, W_{M L} \sim N(0,1), \\
L R_{M L} & =-2\left(L L_{u}-L L_{r}\right), L R_{M L} \sim \chi_{d f=1}^{2}, \\
L M_{M L} & =\frac{1}{n}\left(\hat{\boldsymbol{u}}^{\prime} \boldsymbol{W} \hat{\boldsymbol{u}} / \hat{\sigma}^{2}\right)^{2}, L M_{M L} \sim \chi_{d f=1}^{2},
\end{aligned}
$$

where a '^' refers to ML estimates. $\hat{\sigma}_{\rho}$ is the estimated standard error which is the diagonal element corresponding to $\rho$ in the inverse of the information matrix; $L L_{r}$ $\left(L L_{u}\right)$ is the restricted (unrestricted) log-likelihood. In our case $L L_{r}$ is obtained by an ordinary regression. $d f=1$ is short for 1 degree of freedom.

Under GMM-estimation, a Wald-type test based on the parametric variance estimate following Kelejian and Prucha (2005a) can be employed to test for $\rho=0$. This test may serve as an alternative to the frequently used Moran $I$ test under GMM (see Cliff and Ord, 1981; Kelejian and Prucha, 2001).

\section{Design of Monte Carlo Experiments}

The regression part of our model is $\beta_{0}+\beta_{1} x_{i}$, where we choose $\beta_{0}=\beta_{1}=1$. We assume that $x_{i}$ is uniformly distributed in the interval $[0,1]$. In order to generate the weighting scheme, the observation units are randomly placed on a grid of different sizes (see Table 1). The weighting matrix $\boldsymbol{W}$ exhibits typical elements $W_{i j}=e^{-d_{i j}}$, for $i \neq j$ and $W_{i i}=0$, where $d_{i j}$ is the Euklidean distance between grid points $i$ and $j$. If $d_{i j}>7$ we set $W_{i j}=0$ to limit the memory of the spatial process. 
Table 1: Characteristics of Spatial Weights

\begin{tabular}{ccc}
\hline $\mathrm{n}$ & Lattice $^{\mathrm{a}}$ & Sparseness $^{\mathrm{b}}$ \\
\hline 100 & $20 \times 20$ & 0.751 \\
100 & $32 \times 32$ & 0.889 \\
250 & $32 \times 32$ & 0.883 \\
500 & $32 \times 32$ & 0.879 \\
500 & $45 \times 45$ & 0.935 \\
\hline
\end{tabular}

${ }^{a}$ Only irregular lattices are considered.

${ }^{\mathrm{b}}$ Percentage of zero entries in weighting matrix $\mathbf{W}$.

We consider two different lattices for sample sizes of $n=100$ and $n=500$ to infer the properties of the tests regarding the sparseness of the weighting matrix (see Table 1 ). The SAR parameter $\rho$ varies between -0.5 and 0.5 in steps of 0.1 . We focus on the performance of the three (Wald-, LR-, and LM-type) test statistics based on MLE versus the Wald-test based on GMM estimates. Since the performance of GMM versus MLE is expected to face a trade-off between sample size and deviation from the assumption of normally distributed remainder errors, we consider three sample sizes $(n=100,250,500)$ and three different underlying error distributions. Following Kelejian and Prucha (1999) and Anselin and Moreno (2003), we consider a normal, a lognormal, and a mixture of normal and lognormal distributions of the disturbances (referred to as 'mixed normal errors'). In the benchmark case of normally distributed errors, we assume that $\varepsilon_{i}$ are $i . i . d . N(0,1)$ with $i=1, \ldots, n$. Alternatively, we use the standardized version of the lognormal distribution. We assume in this case that $\varepsilon_{i}=\left[\exp \left(\xi_{i}\right)-\exp (0.5)\right] /[\exp (2)-\exp (1)]^{0.5}$, where the $\xi_{i}$ are i.i.d. $N(0,1)$. The standardization implies that the $\varepsilon_{i}$ are i.i.d. $(0,1)$. This lognormal distribution is positively skewed. The third distribution is a standardized version of a mixture of normals in which a normally distributed random variable $\left(\xi_{i}\right)$ is contaminated by another $\left(\eta_{i}\right)$ that has a larger variance; the $\xi_{i}$ are $i . i . d . N(0,1)$, and the $\eta_{i}$ are $i . i . d . N(0,100)$. We assume that $\varepsilon_{i}=\left[\lambda_{i} \xi_{i}+\left(1-\lambda_{i}\right) \eta_{i}\right] /(5.95)^{0.5}$, where the $\lambda_{i}$ are i.i.d. Bernoulli variables with $\operatorname{Prob}\left(\lambda_{i}=1\right)=0.95$. Also the processes $\lambda_{i}$, $\xi_{i}$, and $\eta_{i}$ are assumed to be jointly independent. Again the standardization implies that the $\varepsilon_{i}$ are i.i.d. $(0,1)$. This distribution exhibits thicker tails than the normal. 
Altogether, we analyze 165 experiments,${ }^{4}$ for each of which we conduct 1000 Monte Carlo runs. The main results can be summarized as follows.

\section{Monte Carlo Simulation Results}

\subsection{Size of the Tests}

Tables $2-4$ summarize the rejection frequencies of the considered tests under $H_{0}$ using the 5 percent critical value significance level to investigate the size of the tests in small and medium sized samples.

Table 2: Empirical rejection frequencies under $\mathrm{H}_{0}$, normal $(\alpha=0.05 ; 1000$ replications)

\begin{tabular}{|c|c|c|c|c|c|c|}
\hline \multirow{2}{*}{$\mathrm{n}$} & \multirow{2}{*}{ Sparseness } & \multicolumn{3}{|c|}{ MLE } & \multirow{2}{*}{$\begin{array}{l}\text { GMM } \\
\text { Wald }\end{array}$} & \multirow{2}{*}{$\frac{\text { GMM eff. }}{\text { Wald }}$} \\
\hline & & Wald & $\overline{\mathrm{LM}}$ & $\overline{\mathrm{LR}}$ & & \\
\hline 100 & 0.751 & 0.069 & 0.040 & 0.056 & 0.055 & 0.053 \\
\hline 100 & 0.889 & 0.075 & 0.067 & 0.057 & 0.060 & 0.060 \\
\hline 250 & 0.883 & 0.054 & 0.047 & 0.044 & 0.049 & 0.045 \\
\hline 500 & 0.879 & 0.063 & 0.065 & 0.055 & 0.057 & 0.056 \\
\hline 500 & 0.935 & 0.044 & 0.043 & 0.040 & 0.045 & 0.040 \\
\hline
\end{tabular}

Let us first focus on Table 2, where the errors are drawn from a normal distribution. All considered tests tend to be properly sized even in samples of moderate size, and as sample size increases the rejection frequencies converge to the true ones as expected. In particular, the GMM Wald-test performs as well as MLE-based tests with respect to test size even in small samples.

\footnotetext{
${ }^{4}$ Three error processes (normal, lognormal, mixed normal), eleven values of the SAR parameter $\rho=[-0.5,-0.4, \ldots, 0.4,0.5]$, and three sample sizes $(n=100,250,500)$. Additionally, we run all experiments for $n=100$ and $n=500$ for alternative lattices.
} 
Table 3: Empirical rejection frequencies under $\mathrm{H}_{0}$, lognormal $(\alpha=0.05 ; 1000$ replications)

\begin{tabular}{|c|c|c|c|c|c|c|}
\hline \multirow{2}{*}{$\mathrm{n}$} & \multirow{2}{*}{ Sparseness } & \multicolumn{3}{|c|}{ MLE } & \multirow{2}{*}{$\begin{array}{l}\text { GMM } \\
\text { Wald }\end{array}$} & \multirow{2}{*}{$\frac{\text { GMM eff. }}{\text { Wald }}$} \\
\hline & & Wald & $\overline{\mathrm{LM}}$ & $\mathrm{LR}$ & & \\
\hline 100 & 0.751 & 0.047 & 0.032 & 0.038 & 0.029 & 0.048 \\
\hline 100 & 0.889 & 0.044 & 0.030 & 0.033 & 0.046 & 0.083 \\
\hline 250 & 0.883 & 0.056 & 0.052 & 0.051 & 0.049 & 0.065 \\
\hline 500 & 0.879 & 0.047 & 0.043 & 0.033 & 0.040 & 0.046 \\
\hline 500 & 0.935 & 0.042 & 0.042 & 0.039 & 0.050 & 0.057 \\
\hline
\end{tabular}

If the errors follow a lognormal distribution (Table 3), the size of the MLE-based tests tends to be slightly lower than in the case of normally distributed errors, specifically in case of the the LM- and LR-MLE based tests. Note, this is not the case for the GMM-based Wald-tests.

Table 4: Empirical rejection frequencies under $\mathrm{H}_{0}$, mixed normal $(\alpha=0.05 ; 1000$ replications)

\begin{tabular}{|c|c|c|c|c|c|c|}
\hline \multirow{2}{*}{$\mathrm{n}$} & \multirow{2}{*}{ Sparseness } & \multicolumn{3}{|c|}{ MLE } & \multirow{2}{*}{$\begin{array}{l}\text { GMM } \\
\text { Wald }\end{array}$} & \multirow{2}{*}{$\frac{\text { GMM eff. }}{\text { Wald }}$} \\
\hline & & Wald & $\overline{\mathrm{LM}}$ & $\mathrm{LR}$ & & \\
\hline 100 & 0.751 & 0.047 & 0.030 & 0.039 & 0.044 & 0.062 \\
\hline 100 & 0.889 & 0.049 & 0.039 & 0.034 & 0.049 & 0.066 \\
\hline 250 & 0.883 & 0.056 & 0.046 & 0.050 & 0.052 & 0.078 \\
\hline 500 & 0.879 & 0.043 & 0.043 & 0.047 & 0.045 & 0.058 \\
\hline 500 & 0.935 & 0.054 & 0.049 & 0.047 & 0.057 & 0.060 \\
\hline
\end{tabular}

The results for mixed normally distributed errors in Table 4 indicate that in small samples ( $n=100$ in our case) the size distortion of the tests is somewhat smaller than for lognormally distributed errors. With more observations, the MLE-based tests perform quite well and exhibit approximately the same size as in the lognormal case. The GMM based test which relies on the asymptotically efficient weighting scheme is oversized. However, with just a few exceptions the GMM-based Waldtest based on the simple weighting scheme is properly sized in all cases and can be recommended for applied research in this respect.

Figures $1-5$ provide further details on the size of the tests at various critical values. These figures correspond to p-value plots suggested by Davidson and MacKinnon 


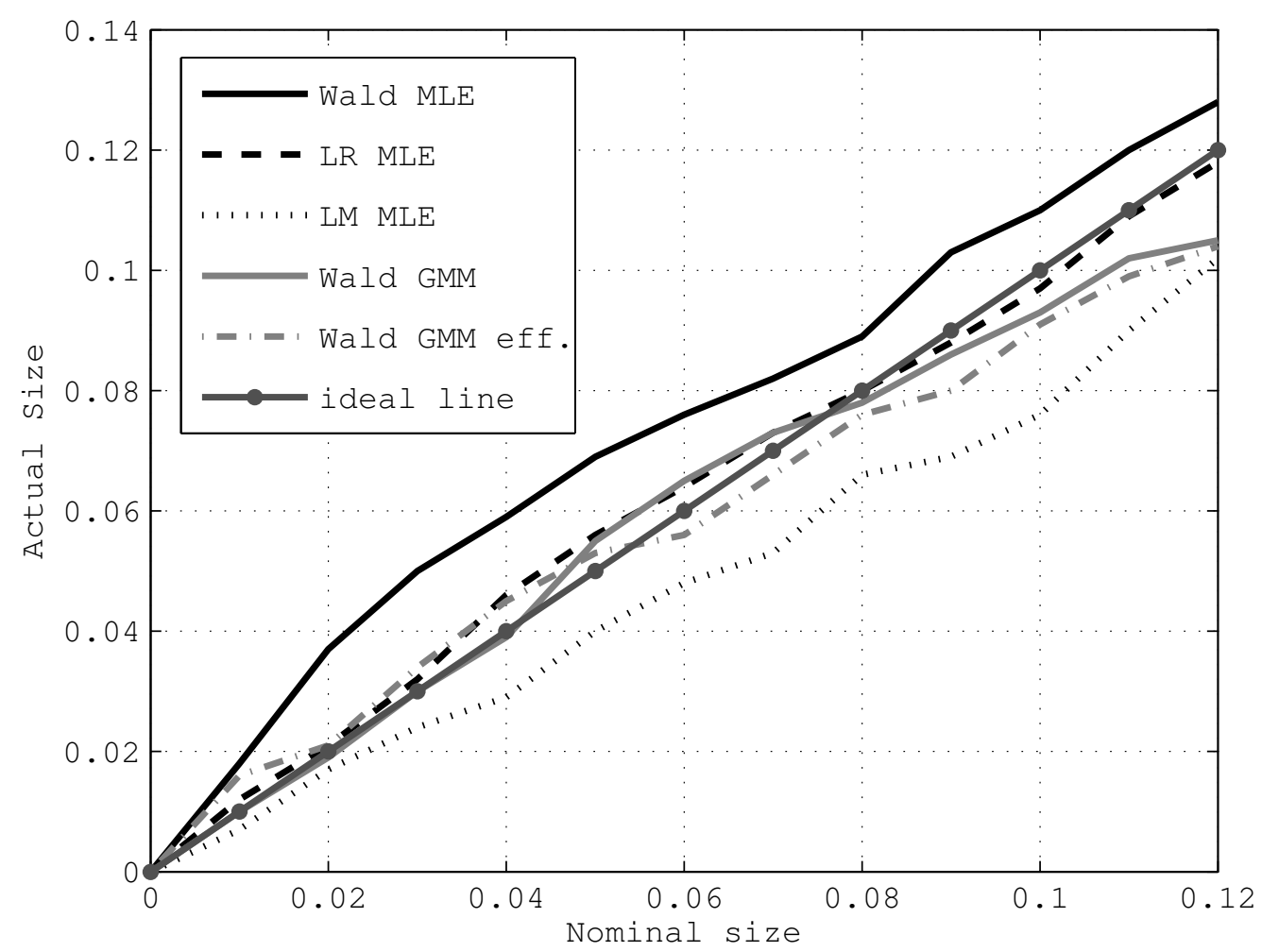

Figure 1: P-value plots for tests regarding $H_{0}: \rho=0$ given normally distributed errors, $n=100$. Lattice size is 20 by 20 .

(1998) for three different sample sizes $(n=100,250,500)$. For sample sizes of 100 and 500, we illustrate how an increasing lattice size, which is equivalent to an increasing sparseness of the spatial weighting matrix at given $n$, changes the size of the various test statistics. Applied researchers typically pay attention only to Type I errors, and hypothesis tests are usually carried out at levels of 10 percent or smaller. Therefore, we focus on values of $p \leq 0.12$ on the abscissa of the plots. Ideally, actual size would coincide with nominal size, reflected by the locus referred to as the ideal line in the figures.

The figures indicate that both the GMM-based Wald-test and the MLE-based LRstatistic work very well, even in small samples of $n=100$. According to Figure 1, the GMM-based Wald-test outperforms the MLE-based LM- and Wald-tests in terms of size, if the sample size is small. The former tends to be undersized, and 


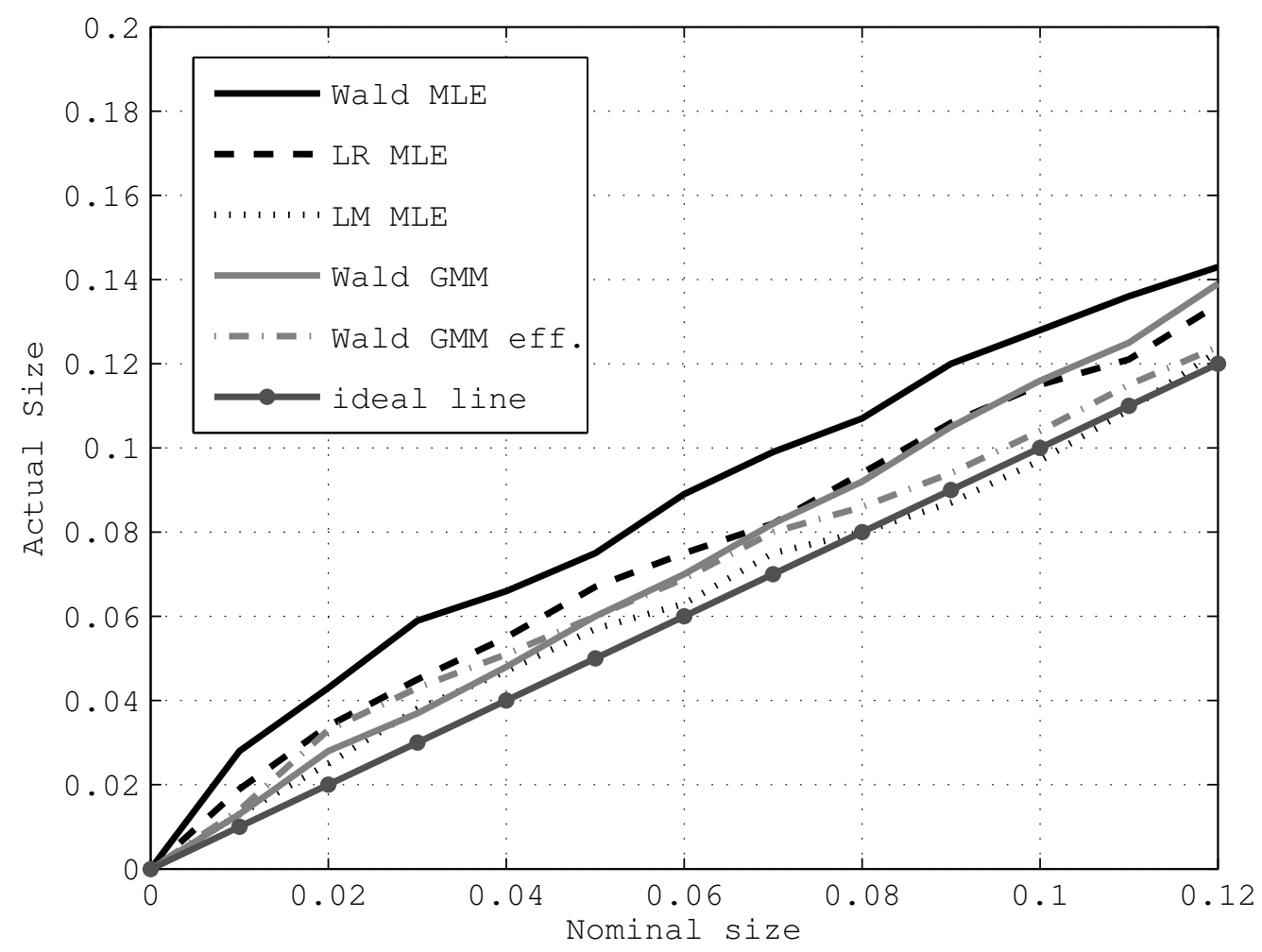

Figure 2: P-value plots for tests regarding $H_{0}: \rho=0$ given normally distributed errors, $n=100$. Lattice size is 32 by 32 .

the latter is oversized. As expected, the performance in terms of actual size of all tests considered in Figures $1-5$ improves as we increase the sample size. For this, compare Figures 1,3 , and $5 .^{5}$

The performance of the tests relative to each other is similar in case of lognormally or mixed normally distributed errors (these figures are not reported for the sake of brevity but available from the authors upon request). If anything, the deviations from the ideal line tend to be stronger as we deviate from the normal error distribution. Also, the convergence of the p-value loci for the various tests towards the ideal line is slower as the sample size increases than with normally distributed errors.

\footnotetext{
${ }^{5}$ Note that the number of observations increases in the same way as the number of cells on the respective lattice. Hence, the sparseness increases as $n$ increases.
} 


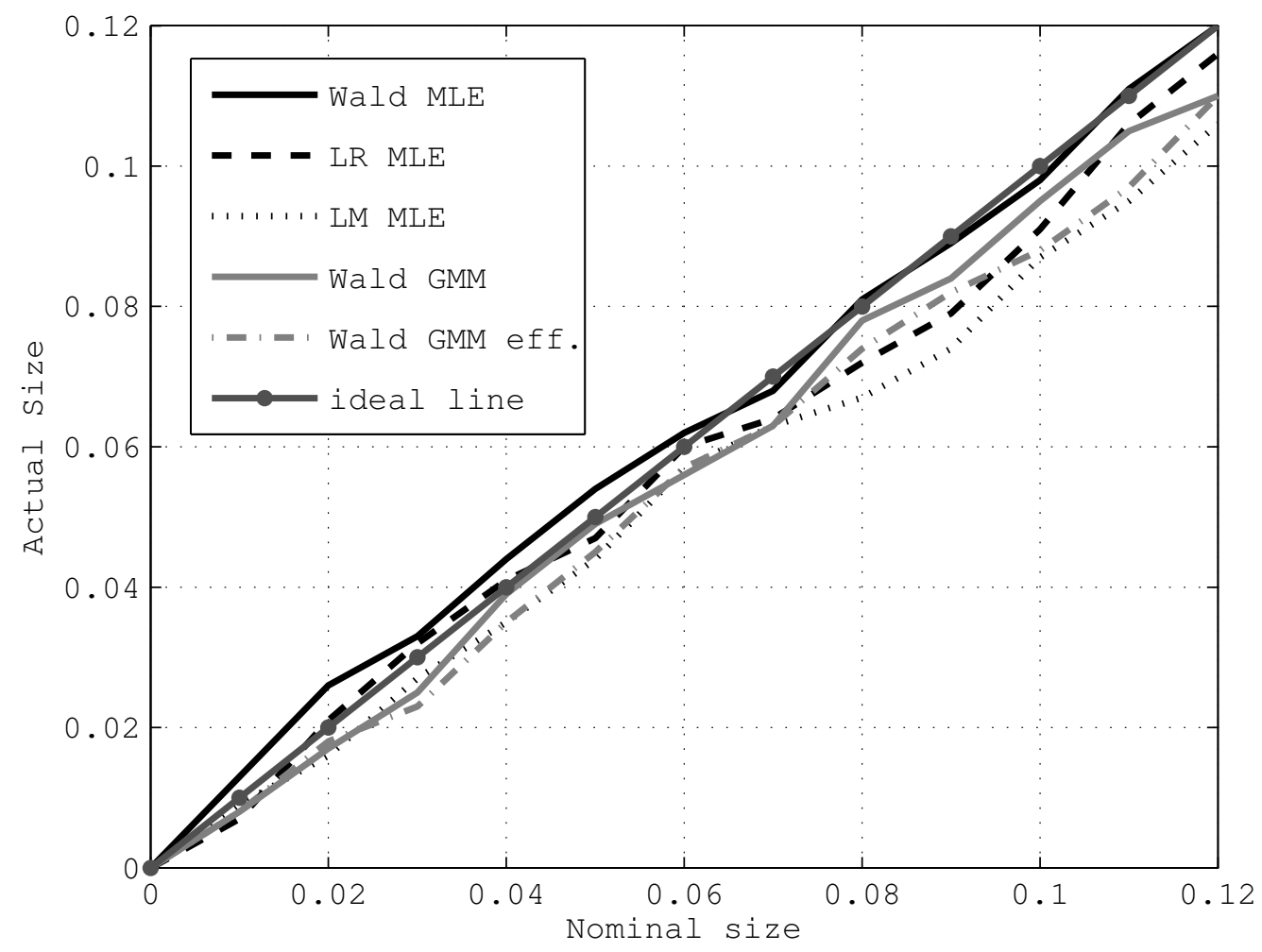

Figure 3: P-value plots for tests regarding $H_{0}: \rho=0$ given normally distributed errors, $n=250$. Lattice size is 32 by 32 . 


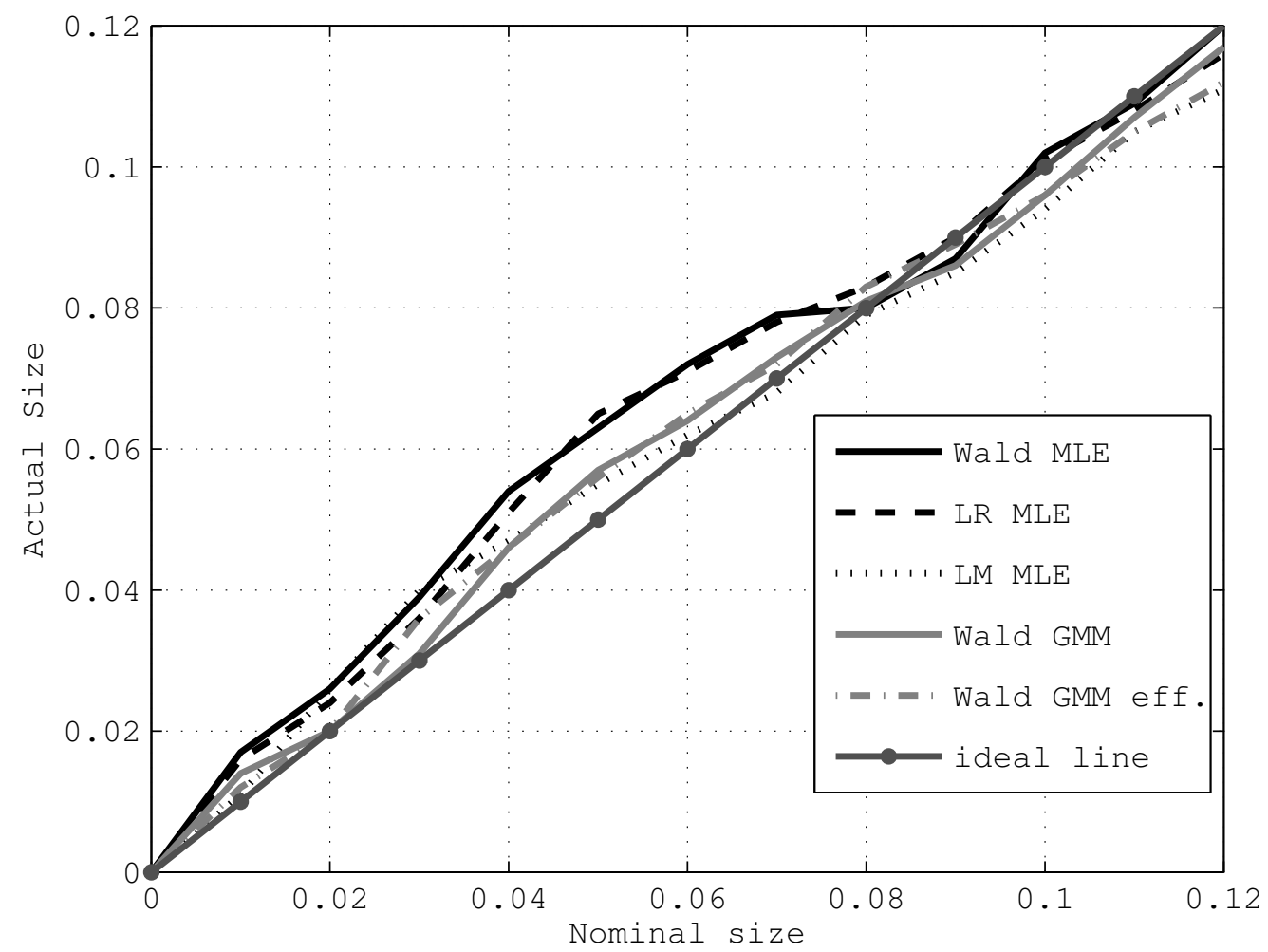

Figure 4: P-value plots for tests regarding $H_{0}: \rho=0$ given normally distributed errors, $n=500$. Lattice size is 32 by 32 . 


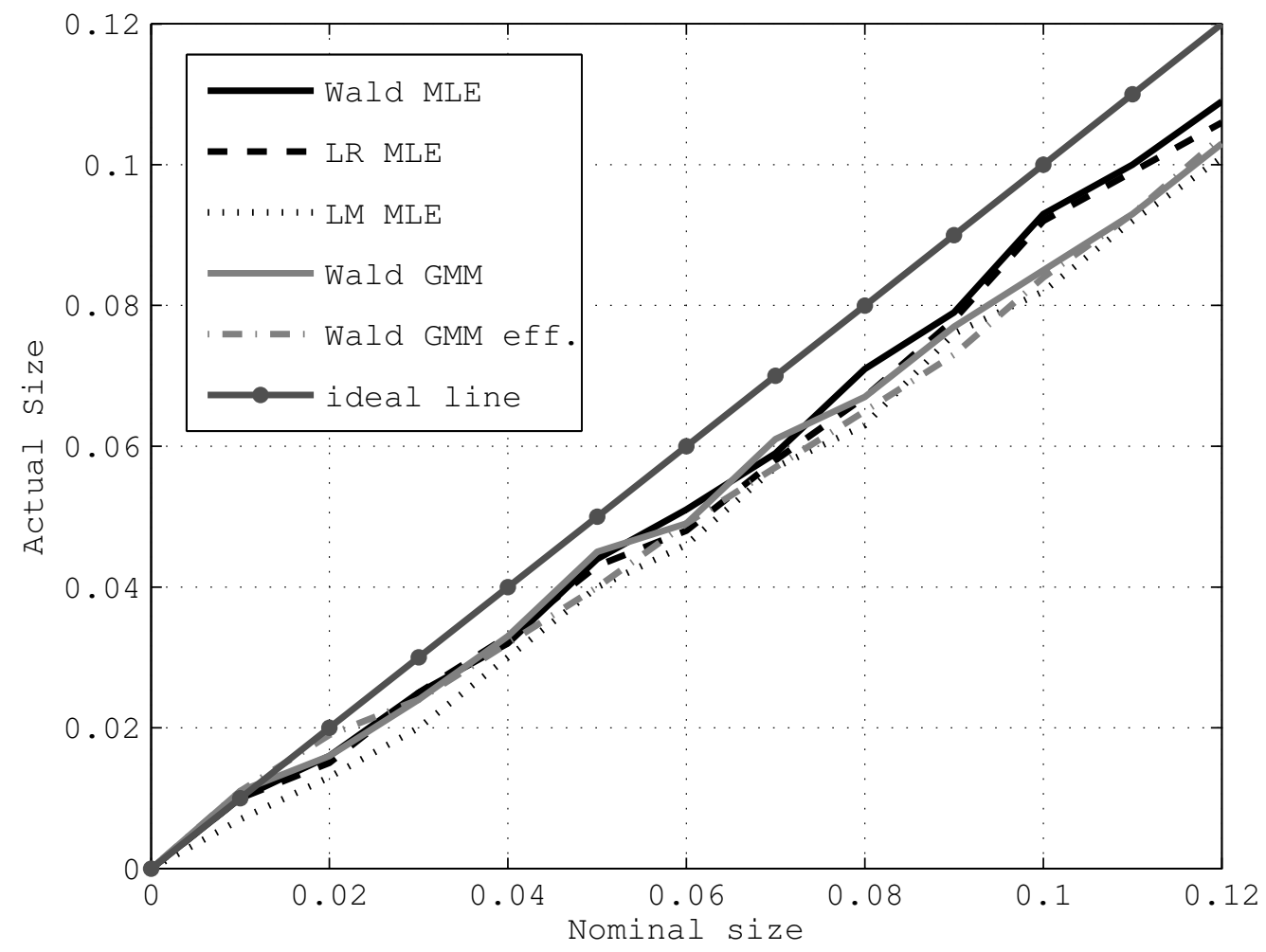

Figure 5: P-value plots for tests regarding $H_{0}: \rho=0$ given normally distributed errors, $n=500$. Lattice size is 45 by 45 . 


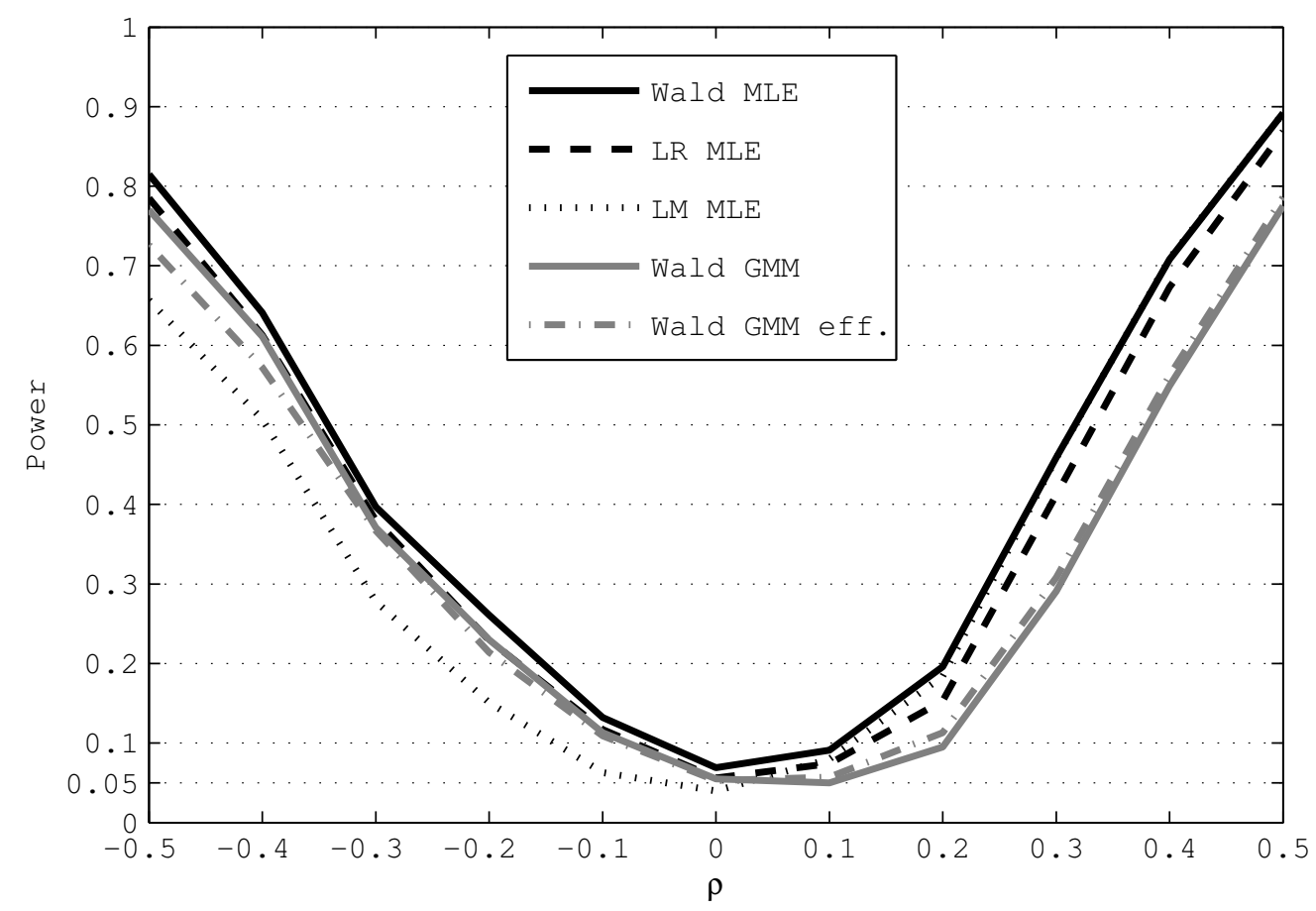

Figure 6: Power function for tests regarding $H_{0}: \rho=0$ at a significance level of $5 \%$ given normally distributed errors, $n=100$. Lattice size is 20 by 20 .

\subsection{Power of the Tests}

We use a nominal size of 0.05 and 11 different values of the spatial autocorrelation parameter $\rho$ in the interval $[-0.5,-0.4, \ldots, 0.4,0.5]$ to compare the five considered test statistics with respect to their power. Our findings are illustrated graphically for the case of normally distributed errors in Figures 6 - 10, where we plot the power function for all (MLE-based and GMM-based) tests corresponding to a sample size of 100, 250, and 500, respectively. Again, we illustrate how the power of the tests depends on the sparseness of the weighting scheme at given $n$. For this, compare Figure 6 with Figure 7 and Figure 9 with Figure 10, respectively.

Two observations are worth noting. First, the power functions are asymmetric with respect to $\rho$. Especially, this is the case in small samples and at a low sparseness of the weighting matrix (see Figure 6). At $n=100$ the MLE-based LM-test exhibits lower power for negative values of $\rho$ as compared to the other test. If $\rho$ is positive, 


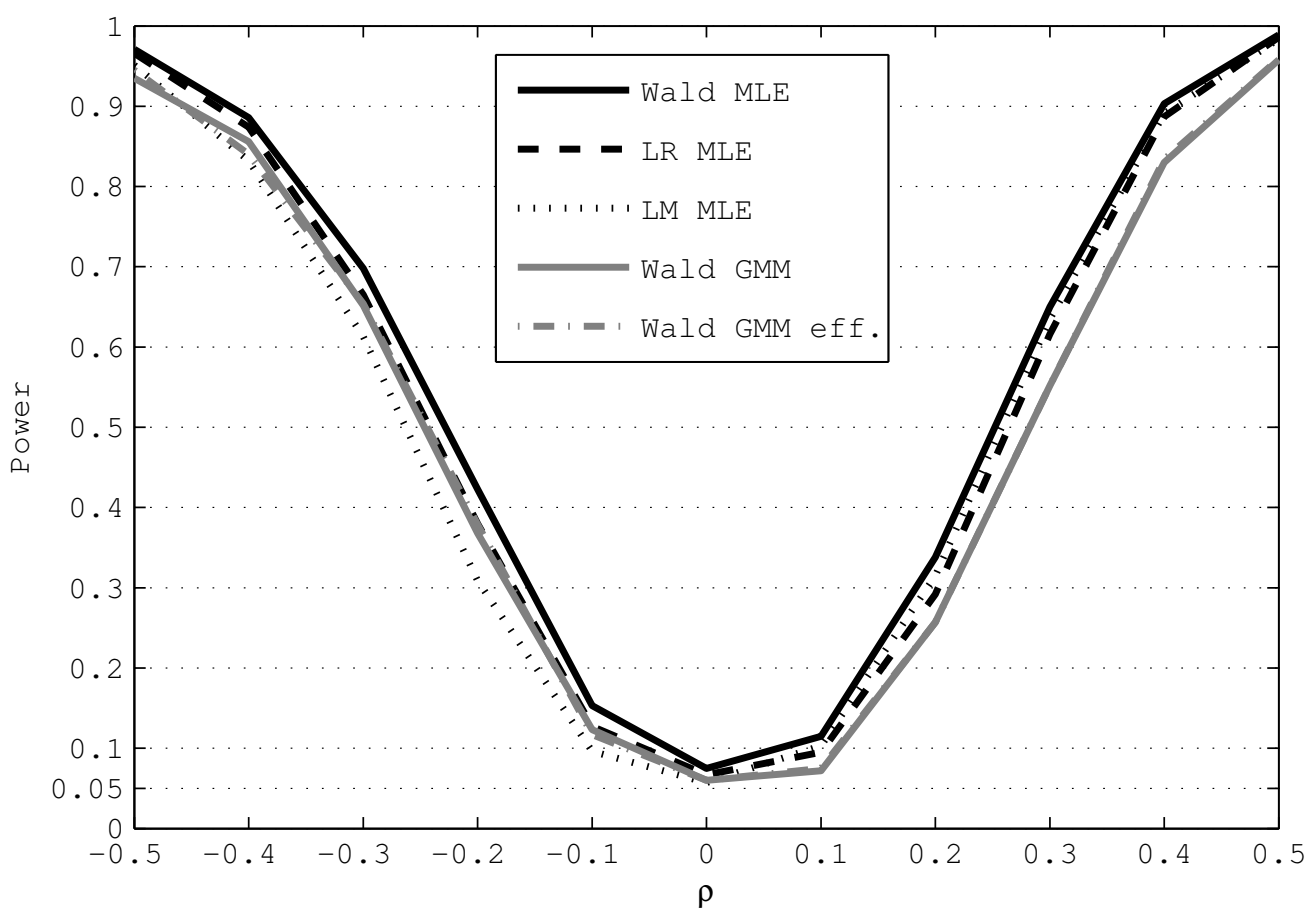

Figure 7: Power function for tests regarding $H_{0}: \rho=0$ at a significance level of $5 \%$ given normally distributed errors, $n=100$. Lattice size is 32 by 32 . 


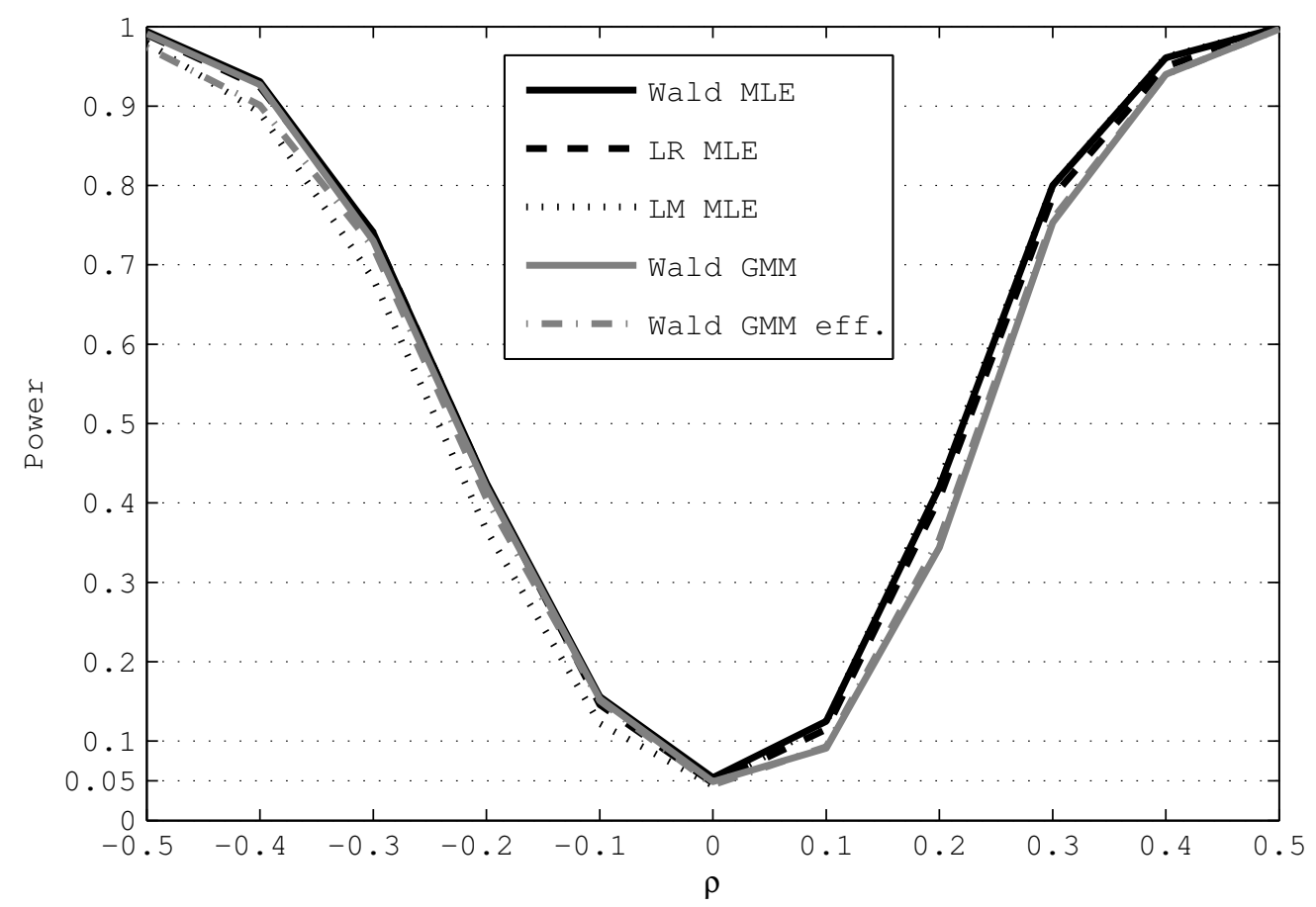

Figure 8: Power function for tests regarding $H_{0}: \rho=0$ at a significance level of $5 \%$ given normally distributed errors, $n=250$. Lattice size is 32 by 32 . 


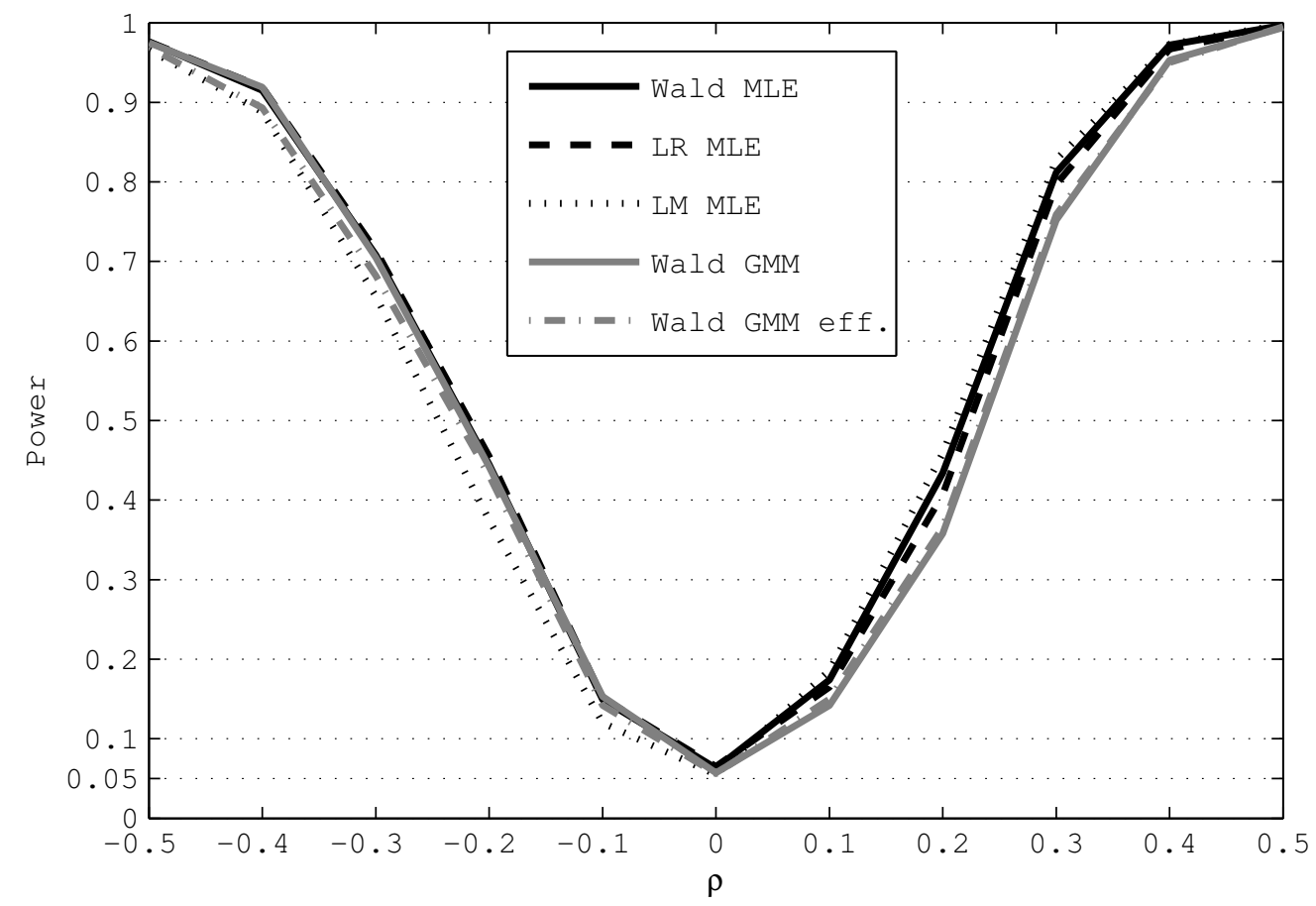

Figure 9: Power function for tests regarding $H_{0}: \rho=0$ at a significance level of $5 \%$ given normally distributed errors, $n=500$. Lattice size is 32 by 32 . 


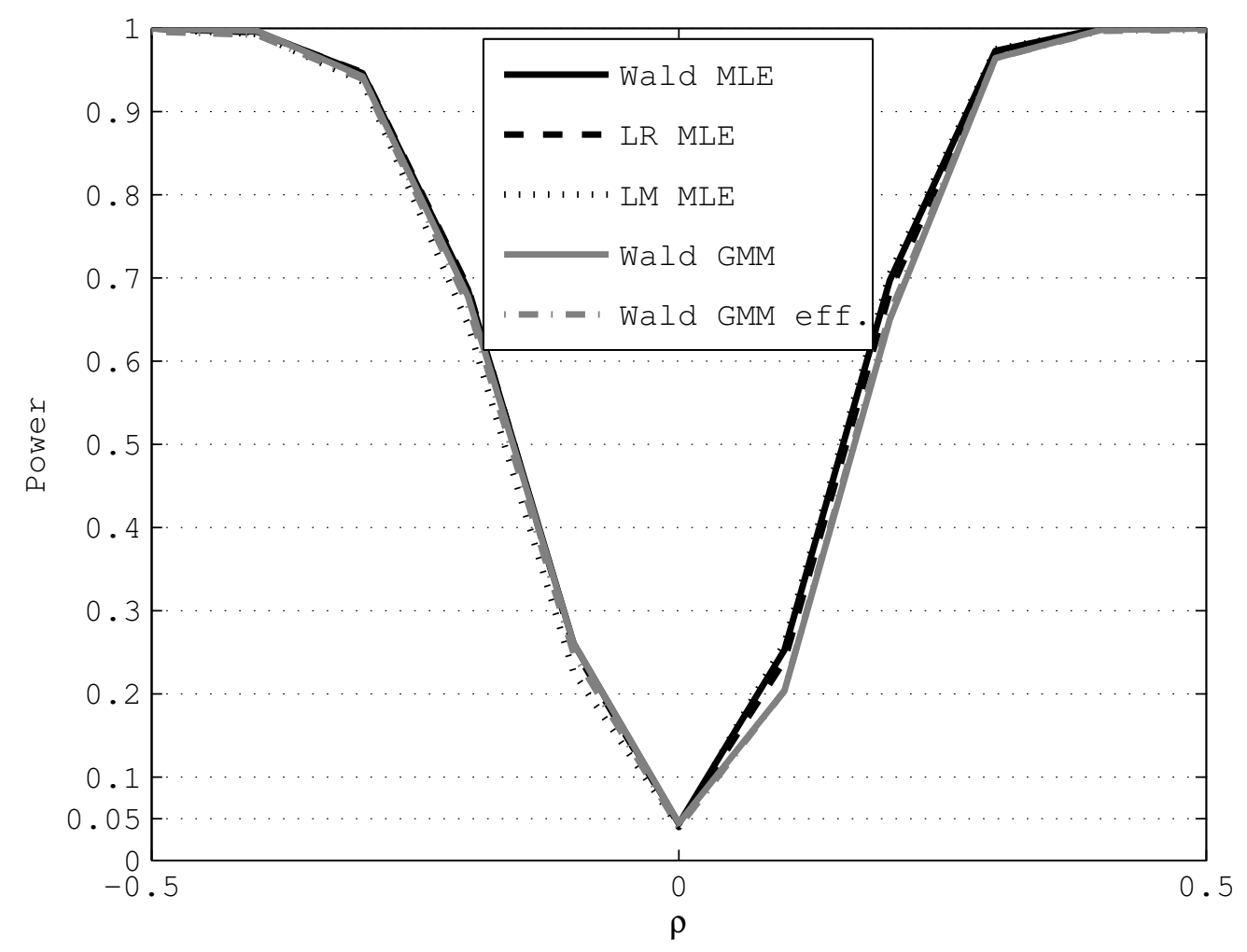

Figure 10: Power function for tests regarding $H_{0}: \rho=0$ at a significance level of $5 \%$ given normally distributed errors, $n=500$. Lattice size is 45 by 45 . 
the power of the GMM-based tests is somewhat lower. One has to bear in mind, however, that the MLE-based LM-test tends to be undersized and the MLE-based LR-test is oversized in small samples. This fact also contributes to the differences in the power function. Second and not very surprisingly, the power functions of all tests (i) exhibit narrower waists and (ii) become more similar as the sample size $n$ grows larger.

So far, we have focused on normally distributed errors. The power functions for lognormally and mixed normally distributed errors are summarized in Tables 5 and 6. Two results are especially worth paying attention to. First, for lognormally distributed errors (see Table 5) the MLE-based Wald test and the GMM-based Wald-test seem most reliable regarding their size and power in small to medium sized samples. Second, these two tests exhibit higher power than the MLE-based LM-test if $\rho$ is much smaller than zero. Similar findings are obtained in case of mixed normally distributed errors. However, in this case also the MLE-based LRtest performs quite well and exhibits high power even in small samples. The MLEbased Wald- and LR-tests as well as the GMM-based Wald-test work better than the MLE-based LM-test if $\rho$ is much smaller than zero.

Finally, we briefly summarize the importance of the sample size $(n)$, the sparseness of the population of spatial lattices (Sparseness, Sparseness $\times \rho^{2}$ ), the sign and size of the SAR parameter $\left(\rho, \rho^{2}, n \times \rho^{2}\right)$, and the deviation from a normal error distribution (Lognormal $\times \rho^{2}$, Mixed Normal $\times \rho^{2}$ ) for the power of the tests by means of response surface regressions. ${ }^{6}$ The logistically transformed rejection probabilities are employed as the dependent variables throughout. We run separate regression models for each type of the considered test statistics. Table 7 reports the corresponding response surface parameter estimates. Here, we only highlight the most important results.

First, there is an overall negative impact of sample size on the rejection probability. The reason for this is that the tests tend to be oversized in small samples. Second, the power functions are parabolic as indicated by the significantly positive coefficient

\footnotetext{
${ }^{6}$ Also, we have estimated a set of less parsimonious specifications that includes the main effects of Lognormal and Mixed Normal. However, it turns out that these determinants do not contribute significantly to the explanation of the rejection probabilities.
} 
Table 5: Power function, lognormal $(\alpha=0.05 ; 1000 \text { replications })^{a}$

\begin{tabular}{|c|c|c|c|c|c|c|}
\hline \multirow{2}{*}{$n$} & \multirow{2}{*}{$\rho$} & \multicolumn{3}{|c|}{ MLE } & \multirow{2}{*}{$\begin{array}{l}\text { GMM } \\
\text { Wald }\end{array}$} & \multirow{2}{*}{$\frac{\text { GMM eff }}{\text { Wald }}$} \\
\hline & & Wald & LM & $\mathrm{LR}$ & & \\
\hline \multirow[t]{11}{*}{100} & -0.5 & 0.843 & 0.678 & 0.808 & 0.822 & 0.729 \\
\hline & -0.4 & 0.647 & 0.449 & 0.605 & 0.609 & 0.536 \\
\hline & -0.3 & 0.444 & 0.282 & 0.407 & 0.412 & 0.372 \\
\hline & -0.2 & 0.230 & 0.126 & 0.199 & 0.202 & 0.228 \\
\hline & -0.1 & 0.076 & 0.038 & 0.068 & 0.062 & 0.109 \\
\hline & 0 & 0.047 & 0.032 & 0.038 & 0.029 & 0.048 \\
\hline & 0.1 & 0.069 & 0.065 & 0.051 & 0.037 & 0.052 \\
\hline & 0.2 & 0.155 & 0.157 & 0.138 & 0.101 & 0.114 \\
\hline & 0.3 & 0.398 & 0.401 & 0.350 & 0.280 & 0.277 \\
\hline & 0.4 & 0.697 & 0.686 & 0.646 & 0.498 & 0.503 \\
\hline & 0.5 & 0.903 & 0.887 & 0.875 & 0.693 & 0.712 \\
\hline \multirow[t]{11}{*}{250} & -0.5 & 0.971 & 0.953 & 0.969 & 0.971 & 0.943 \\
\hline & -0.4 & 0.911 & 0.856 & 0.901 & 0.915 & 0.857 \\
\hline & -0.3 & 0.773 & 0.697 & 0.760 & 0.773 & 0.713 \\
\hline & -0.2 & 0.471 & 0.378 & 0.452 & 0.472 & 0.429 \\
\hline & -0.1 & 0.123 & 0.097 & 0.113 & 0.119 & 0.166 \\
\hline & 0 & 0.056 & 0.052 & 0.051 & 0.049 & 0.065 \\
\hline & 0.1 & 0.129 & 0.129 & 0.119 & 0.104 & 0.108 \\
\hline & 0.2 & 0.399 & 0.417 & 0.388 & 0.336 & 0.314 \\
\hline & 0.3 & 0.810 & 0.793 & 0.779 & 0.690 & 0.658 \\
\hline & 0.4 & 0.980 & 0.972 & 0.972 & 0.908 & 0.885 \\
\hline & 0.5 & 1.000 & 1.000 & 1.000 & 0.994 & 0.985 \\
\hline \multirow[t]{11}{*}{500} & -0.5 & 0.999 & 0.999 & 0.999 & 0.999 & 0.995 \\
\hline & -0.4 & 0.984 & 0.980 & 0.984 & 0.989 & 0.975 \\
\hline & -0.3 & 0.945 & 0.936 & 0.944 & 0.948 & 0.920 \\
\hline & -0.2 & 0.714 & 0.667 & 0.709 & 0.733 & 0.682 \\
\hline & -0.1 & 0.238 & 0.208 & 0.239 & 0.257 & 0.279 \\
\hline & 0 & 0.042 & 0.042 & 0.039 & 0.050 & 0.057 \\
\hline & 0.1 & 0.202 & 0.211 & 0.186 & 0.198 & 0.177 \\
\hline & 0.2 & 0.732 & 0.746 & 0.715 & 0.655 & 0.637 \\
\hline & 0.3 & 0.987 & 0.984 & 0.985 & 0.959 & 0.954 \\
\hline & 0.4 & 1.000 & 1.000 & 1.000 & 0.999 & 0.997 \\
\hline & 0.5 & 1.000 & 1.000 & 1.000 & 1.000 & 0.997 \\
\hline
\end{tabular}

${ }^{a}$ Sparseness is $0.751(n=100), 0.883(n=250)$, and $0.935(n=500)$. 
Table 6: Power function, mixed normal errors $(\alpha=0.05 ; 1000 \text { replications })^{\mathrm{a}}$

\begin{tabular}{|c|c|c|c|c|c|c|}
\hline \multirow{2}{*}{$\mathrm{n}$} & \multirow{2}{*}{$\rho$} & \multicolumn{3}{|c|}{ MLE } & \multirow{2}{*}{$\begin{array}{l}\text { GMM } \\
\text { Wald }\end{array}$} & \multirow{2}{*}{$\begin{array}{c}\text { GMM eff. } \\
\text { Wald }\end{array}$} \\
\hline & & Wald & LM & LR & & \\
\hline \multirow[t]{11}{*}{100} & -0.5 & 0.811 & 0.606 & 0.771 & 0.797 & 0.680 \\
\hline & -0.4 & 0.659 & 0.457 & 0.615 & 0.643 & 0.544 \\
\hline & -0.3 & 0.392 & 0.266 & 0.368 & 0.359 & 0.378 \\
\hline & -0.2 & 0.183 & 0.106 & 0.175 & 0.171 & 0.222 \\
\hline & -0.1 & 0.071 & 0.032 & 0.062 & 0.062 & 0.107 \\
\hline & 0 & 0.047 & 0.030 & 0.039 & 0.044 & 0.062 \\
\hline & 0.1 & 0.068 & 0.067 & 0.056 & 0.055 & 0.071 \\
\hline & 0.2 & 0.193 & 0.210 & 0.164 & 0.157 & 0.164 \\
\hline & 0.3 & 0.472 & 0.478 & 0.426 & 0.324 & 0.329 \\
\hline & 0.4 & 0.763 & 0.717 & 0.691 & 0.511 & 0.518 \\
\hline & 0.5 & 0.913 & 0.890 & 0.882 & 0.702 & 0.714 \\
\hline \multirow[t]{11}{*}{250} & -0.5 & 0.973 & 0.955 & 0.969 & 0.980 & 0.942 \\
\hline & -0.4 & 0.947 & 0.891 & 0.937 & 0.951 & 0.884 \\
\hline & -0.3 & 0.768 & 0.655 & 0.752 & 0.784 & 0.679 \\
\hline & -0.2 & 0.401 & 0.316 & 0.387 & 0.405 & 0.408 \\
\hline & -0.1 & 0.133 & 0.115 & 0.132 & 0.136 & 0.192 \\
\hline & 0 & 0.056 & 0.046 & 0.050 & 0.052 & 0.078 \\
\hline & 0.1 & 0.107 & 0.111 & 0.096 & 0.112 & 0.093 \\
\hline & 0.2 & 0.465 & 0.465 & 0.429 & 0.372 & 0.338 \\
\hline & 0.3 & 0.812 & 0.792 & 0.780 & 0.697 & 0.653 \\
\hline & 0.4 & 0.964 & 0.960 & 0.958 & 0.917 & 0.894 \\
\hline & 0.5 & 0.994 & 0.993 & 0.993 & 0.983 & 0.971 \\
\hline \multirow[t]{11}{*}{500} & -0.5 & 0.997 & 0.997 & 0.997 & 0.998 & 0.994 \\
\hline & -0.4 & 0.994 & 0.994 & 0.994 & 0.994 & 0.988 \\
\hline & -0.3 & 0.955 & 0.934 & 0.951 & 0.956 & 0.929 \\
\hline & -0.2 & 0.698 & 0.635 & 0.693 & 0.714 & 0.666 \\
\hline & -0.1 & 0.220 & 0.180 & 0.213 & 0.231 & 0.246 \\
\hline & 0 & 0.054 & 0.049 & 0.047 & 0.057 & 0.060 \\
\hline & 0.1 & 0.200 & 0.220 & 0.187 & 0.221 & 0.192 \\
\hline & 0.2 & 0.776 & 0.765 & 0.749 & 0.674 & 0.657 \\
\hline & 0.3 & 0.972 & 0.970 & 0.967 & 0.931 & 0.917 \\
\hline & 0.4 & 0.998 & 0.999 & 0.999 & 0.996 & 0.988 \\
\hline & 0.5 & 1.000 & 1.000 & 1.000 & 1.000 & 1.000 \\
\hline
\end{tabular}

${ }^{a}$ Sparseness is $0.751(n=100), 0.883(n=250)$, and $0.935(n=500)$. 
Table 7: Response surface estimation $(\alpha=0.05 ; 1000 \text { replications })^{2}$

\begin{tabular}{|c|c|c|c|c|c|}
\hline \multirow{2}{*}{ Variable $^{\mathrm{b}}$} & \multicolumn{3}{|c|}{ MLE } & \multirow{2}{*}{$\begin{array}{r}\text { GMM } \\
\text { Wald }\end{array}$} & \multirow{2}{*}{$\begin{array}{r}\text { GMM eff. } \\
\text { Wald }\end{array}$} \\
\hline & Wald & $\mathrm{LM}$ & $\overline{\mathrm{LR}}$ & & \\
\hline \multirow[t]{3}{*}{$\rho$} & 0.001 & 0.001 & 0.001 & 0.001 & 0.001 \\
\hline & $(0.001)$ & $(0.001)$ & $(0.001)$ & $(0.001)$ & $(0.001)$ \\
\hline & 0.128 & 0.108 & 0.103 & 0.295 & 0.368 \\
\hline \multirow[t]{3}{*}{$\rho^{2}$} & 0.960 & 1.604 & 0.930 & 0.064 & 0.389 \\
\hline & $(0.222)$ & $(0.231)$ & $(0.237)$ & $(0.248)$ & $(0.200)$ \\
\hline & 0.000 & 0.000 & 0.000 & 0.797 & 0.054 \\
\hline \multirow[t]{3}{*}{$\mathrm{n}$} & -34.322 & -26.179 & -29.497 & -22.145 & -19.123 \\
\hline & $(9.897)$ & $(10.080)$ & $(10.065)$ & $(11.161)$ & $(9.261)$ \\
\hline & 0.001 & 0.010 & 0.004 & 0.049 & 0.041 \\
\hline \multirow[t]{3}{*}{$\mathrm{n} \times \rho^{2}$} & 0.010 & 0.019 & 0.016 & 0.023 & 0.019 \\
\hline & $(0.007)$ & $(0.007)$ & $(0.007)$ & $(0.008)$ & $(0.006)$ \\
\hline & 0.124 & 0.005 & 0.021 & 0.003 & 0.001 \\
\hline \multirow[t]{3}{*}{ Lognormal $\times \rho^{2}$} & 0.054 & -1.373 & -1.141 & -0.990 & -2.116 \\
\hline & $(1.404)$ & $(1.345)$ & (1.428) & (1.608) & $(1.204)$ \\
\hline & 0.970 & 0.309 & 0.425 & 0.539 & 0.081 \\
\hline \multirow[t]{3}{*}{ Mixed Normal $\times \rho^{2}$} & -1.288 & -2.364 & -1.968 & -1.959 & -2.973 \\
\hline & $(1.416)$ & $(1.490)$ & $(1.553)$ & (1.602) & (1.238) \\
\hline & 0.365 & 0.115 & 0.207 & 0.223 & 0.018 \\
\hline \multirow[t]{3}{*}{ Sparseness } & 3.626 & 4.947 & 4.058 & 5.595 & 4.872 \\
\hline & $(1.514)$ & $(1.552)$ & $(1.585)$ & $(1.570)$ & $(1.495)$ \\
\hline & 0.018 & 0.002 & 0.011 & 0.000 & 0.001 \\
\hline \multirow[t]{3}{*}{ Sparseness $\times \rho^{2}$} & 68.179 & 55.969 & 61.099 & 48.276 & 43.720 \\
\hline & $(13.090)$ & (13.213) & $(13.140)$ & $(14.639)$ & (12.129) \\
\hline & 0.000 & 0.000 & 0.000 & 0.001 & 0.000 \\
\hline \multirow[t]{3}{*}{ Constant } & -5.272 & -6.616 & -5.770 & -6.984 & -6.187 \\
\hline & $(1.194)$ & $(1.223)$ & $(1.251)$ & (1.241) & $(1.182)$ \\
\hline & 0.000 & 0.000 & 0.000 & 0.000 & 0.000 \\
\hline $\mathrm{R}^{2}$ & 0.905 & 0.907 & 0.899 & 0.891 & 0.899 \\
\hline
\end{tabular}

${ }^{a}$ OLS regressions with heteroskedasticity-robust standard errors.

${ }^{\mathrm{b}}$ Coefficient estimates; standard errors in parentheses; p-values in italics. 
of $\rho^{2}$. Third, the size and power of the tests seem independent of the choice among the considered error distributions. Only for the efficient GMM-based Wald-test, the power tends to be significantly lower in case of lognormally or mixed normally distributed errors as compared to normally distributed ones. The sparseness of (irregular) spatial weighting matrices is a very important determinant. Both the size and the power of the tests increase significantly with the sparseness of the lattice.

\section{Conclusions}

This paper compares MLE-based and GMM-based tests against spatially autocorrelated errors in Ord-type spatial models. In doing so, we consider a test based on the recently derived parametric estimate of the GMM-based variance of the SAR parameter. The small sample properties are investigated in a Monte-Carlo study.

Assuming different spatial processes, previous research tended to point to a better performance of MLE-based tests rather than GMM-based ones, especially, in small samples. However, our findings do not support this view for testing against SAR. Two versions of a Wald-test based on the variance of the SAR parameter under GMM derived by Kelejian and Prucha (2005a) perform as well as MLE-based tests in case of normally distributed errors. The GMM-based Wald-tests tend to perform extremely well irrespective of the underlying error distribution, and they outperform the MLE-based LM-test in terms of both size and power in small to moderately-sized samples for negative values of the SAR parameter. Across the board (i.e., across sample sizes and error distributions), our results support the use of both MLEbased tests and the GMM-based Wald-tests. Regarding GMM-based Wald-tests, in particular that one based on one-step estimates using the simple fixed moments weighting matrix can be recommended for applied researchers even in small sample applications. 


\section{References}

Anselin, Luc, Spatial Econometrics: Methods and Models, Boston: Kluwer Academic Publishers, 1988.

_ _ "Rao's Score Test in Spatial Econometrics," Journal of Statistical Planning and Inference, 2001, 97 (1), 113-139.

and Raymond J. Florax, Small Sample Properties of Tests for Spatial Dependence in Regression Models: Some Further Results, in: New Directions in Spatial Econometrics, ed. L. Anselin and R.J. Florax, Springer Verlag, Berlin, 1995.

and Rosina Moreno, "Properties of Tests for Spatial Error Components," Regional Science and Urban Economics, 2003, 33 (5), 595-618.

and Sergio J. Rey, "Properties of Tests for Spatial Dependence in Linear Regression Models," Geographical Analysis, 1991, 23 (2), 112-131.

Anil K. Bera, Raymond J. Florax, and Mann J. Yoon, "Simple Diagnostic Tests for Spatial Dependence," Regional Science and Urban Economics, 1996, 26 (1), 77-104.

Burridge, Peter, "On the Cliff-Ord Test for Spatial Autocorrelation," Journal of the Royal Statistical Society, Series B, 1980, 42 (1), 107-108.

Cliff, Andrew D. and J. Keith Ord, Spatial Processes, Models and Applications, London: Pion, 1981.

Conley, Timothy G., "GMM Estimation with Cross Sectional Dependence," Journal of Econometrics, 1999, 92 (1), 1-45.

Davidson, Russell and James G. MacKinnon, "Graphical Methods for Investigating the Size and Power of Hypothesis Tests," The Manchester School, 1998, $66(1), 1-26$.

Kelejian, Harry H. and Dennis P. Robinson, "Spatial Autocorrelation: A New Computationally Simple Test With and Application to Per Capita Country 
Police Expenditures," Regional Science and Urban Economics, 1992, 22 (3), $317-333$.

and _ _ "A Suggested Method of Estimation for Spatial Interdependent Models with Autocorrelated Errors, and an Application to a County Expenditure Model," Papers in Regional Science, 1993, 72 (3), 297-312.

and __ , "Infrastructure Productivity Estimation and its Underlying Econometric Specifications," Papers in Regional Science, 1997, 76 (1), 115-131.

and Ingmar R. Prucha, "A Generalized Moments Estimator for the Autoregressive Parameter in a Spatial Model," International Economic Review, 1999, 40 (2), 509-533.

and _ _ "On the Asymptotic Distribution of the Moran I Test Statistic with Applications," Journal of Econometrics, 2001, 104 (2), 219-257.

and __ , "2SLS and OLS in a Spatial Autoregressiv Model with Equal Spatial Weights," Regional Science and Urban Economics, 2002, 32 (6), 691-707.

and _ , "Specification and Estimation of Spatial Autoregressive Models with Autoregressive and Heteroskedastic Disturbances," unpublished manuscript, University of Maryland, 2005a.

and _ , "HAC Estimation in a Spatial Framework," unpublished manuscript, University of Maryland, 2005b.

Lagarias, Jeffrey C., James A. Reeds, Margaret H. Wright, and Paul E.

Wright, "Convergence Properties of the Nelder-Mead Simplex Method in Low Dimensions," SIAM Journal of Optimization, 1998, 9 (1), 112-147.

Lee, Lung-fei, "Best Spatial Two-Stage Least Squares Estimators for a Spatial Autoregressive Model with Autoregressive Disturbances," Econometric Reviews, 2003, 22 (4), 307-335.

, "Asymptotic Distributions of Quasi-Maximum Likelihood Estimators for Spatial Autoregressive Models," Econometrica, 2004, 72 (6), 1899-1925. 
Ord, J. Keith, "Estimation Methods for Models of Spatial Interactions," Journal of the American Statistical Association, 1975, 70 (349), 120-26.

Pinkse, Joris, Margaret E. Slade, and Craig Brett, "Spatial Price Competition: A Semiparametric Approach," Econometrica, 2002, 70 (3), 1111-1153.

Saavedra, Luz A., "Tests for Spatial Lag Dependence Based on Method of Moments Estimation," Regional Science and Urban Economics, 2003, 33 (1), 27 58. 


\section{CESifo Working Paper Series}

(for full list see www.cesifo-group.de)

1493 Kurt R. Brekke and Michael Kuhn, Direct to Consumer Advertising in Pharmaceutical Markets, July 2005

1494 Martín Gonzalez-Eiras and Dirk Niepelt, Sustaining Social Security, July 2005

1495 Alfons J. Weichenrieder, (Why) Do we need Corporate Taxation?, July 2005

1496 Paolo M. Panteghini, S-Based Taxation under Default Risk, July 2005

1497 Panos Hatzipanayotou and Michael S. Michael, Migration, Tied Foreign Aid and the Welfare State, July 2005

1498 Agata Antkiewicz and John Whalley, BRICSAM and the Non-WTO, July 2005

1499 Petr Hedbávný, Ondřej Schneider and Jan Zápal, A Fiscal Rule that has Teeth: A Suggestion for a 'Fiscal Sustainability Council' underpinned by the Financial Markets, July 2005

1500 J. Atsu Amegashie and Marco Runkel, Sabotaging Potential Rivals, July 2005

1501 Heikki Oksanen, Actuarial Neutrality across Generations Applied to Public Pensions under Population Ageing: Effects on Government Finances and National Saving, July 2005

1502 Xenia Matschke, Costly Revenue-Raising and the Case for Favoring Import-Competing Industries, July 2005

1503 Horst Raff and Nicolas Schmitt, Why Parallel Trade may Raise Producers Profits, July 2005

1504 Alberto Bisin and Piero Gottardi, Efficient Competitive Equilibria with Adverse Selection, July 2005

1505 Peter A. Zadrozny, Necessary and Sufficient Restrictions for Existence of a Unique Fourth Moment of a Univariate GARCH(p,q) Process, July 2005

1506 Rainer Niemann and Corinna Treisch, Group Taxation, Asymmetric Taxation and Cross-Border Investment Incentives in Austria, July 2005

1507 Thomas Christiaans, Thomas Eichner and Ruediger Pethig, Optimal Pest Control in Agriculture, July 2005

1508 Biswa N. Bhattacharyay and Prabir De, Promotion of Trade and Investments between China and India: The Case of Southwest China and East and Northeast India, July 2005 
1509 Jean Hindriks and Ben Lockwood, Decentralization and Electoral Accountability: Incentives, Separation, and Voter Welfare, July 2005

1510 Michelle R. Garfinkel, Stergios Skaperdas and Constantinos Syropoulos, Globalization and Domestic Conflict, July 2005

1511 Jesús Crespo-Cuaresma, Balázs Égert and Ronald MacDonald, Non-Linear Exchange Rate Dynamics in Target Zones: A Bumpy Road towards a Honeymoon - Some Evidence from the ERM, ERM2 and Selected New EU Member States, July 2005

1512 David S. Evans and Michael Salinger, Curing Sinus Headaches and Tying Law: An Empirical Analysis of Bundling Decongestants and Pain Relievers, August 2005

1513 Christian Keuschnigg and Martin D. Dietz, A Growth Oriented Dual Income Tax, July 2005

1514 Fahad Khalil, David Martimort and Bruno Parigi, Monitoring a Common Agent: Implications for Financial Contracting, August 2005

1515 Volker Grossmann and Panu Poutvaara, Pareto-Improving Bequest Taxation, August 2005

1516 Lars P. Feld and Emmanuelle Reulier, Strategic Tax Competition in Switzerland: Evidence from a Panel of the Swiss Cantons, August 2005

1517 Kira Boerner and Silke Uebelmesser, Migration and the Welfare State: The Economic Power of the Non-Voter?, August 2005

1518 Gabriela Schütz, Heinrich W. Ursprung and Ludger Wößmann, Education Policy and Equality of Opportunity, August 2005

1519 David S. Evans and Michael A. Salinger, Curing Sinus Headaches and Tying Law: An Empirical Analysis of Bundling Decongestants and Pain Relievers, August 2005

1520 Michel Beine, Paul De Grauwe and Marianna Grimaldi, The Impact of FX Central Bank Intervention in a Noise Trading Framework, August 2005

1521 Volker Meier and Matthias Wrede, Pension, Fertility, and Education, August 2005

1522 Saku Aura and Thomas Davidoff, Optimal Commodity Taxation when Land and Structures must be Taxed at the Same Rate, August 2005

1523 Andreas Haufler and Søren Bo Nielsen, Merger Policy to Promote 'Global Players'? A Simple Model, August 2005

1524 Frederick van der Ploeg, The Making of Cultural Policy: A European Perspective, August 2005

1525 Alexander Kemnitz, Can Immigrant Employment Alleviate the Demographic Burden? The Role of Union Centralization, August 2005 
1526 Baoline Chen and Peter A. Zadrozny, Estimated U.S. Manufacturing Production Capital and Technology Based on an Estimated Dynamic Economic Model, August 2005

1527 Marcel Gérard, Multijurisdictional Firms and Governments' Strategies under Alternative Tax Designs, August 2005

1528 Joerg Breitscheidel and Hans Gersbach, Self-Financing Environmental Mechanisms, August 2005

1529 Giorgio Fazio, Ronald MacDonald and Jacques Mélitz, Trade Costs, Trade Balances and Current Accounts: An Application of Gravity to Multilateral Trade, August 2005

1530 Thomas Christiaans, Thomas Eichner and Ruediger Pethig, A Micro-Level 'Consumer Approach' to Species Population Dynamics, August 2005

1531 Samuel Hanson, M. Hashem Pesaran and Til Schuermann, Firm Heterogeneity and Credit Risk Diversification, August 2005

1532 Mark Mink and Jakob de Haan, Has the Stability and Growth Pact Impeded Political Budget Cycles in the European Union?, September 2005

1533 Roberta Colavecchio, Declan Curran and Michael Funke, Drifting Together or Falling Apart? The Empirics of Regional Economic Growth in Post-Unification Germany, September 2005

1534 Kai A. Konrad and Stergios Skaperdas, Succession Rules and Leadership Rents, September 2005

1535 Robert Dur and Amihai Glazer, The Desire for Impact, September 2005

1536 Wolfgang Buchholz and Wolfgang Peters, Justifying the Lindahl Solution as an Outcome of Fair Cooperation, September 2005

1537 Pieter A. Gautier, Coen N. Teulings and Aico van Vuuren, On-the-Job Search and Sorting, September 2005

1538 Leif Danziger, Output Effects of Inflation with Fixed Price- and Quantity-Adjustment Costs, September 2005

1539 Gerhard Glomm, Juergen Jung, Changmin Lee and Chung Tran, Public Pensions and Capital Accumulation: The Case of Brazil, September 2005

1540 Yvonne Adema, Lex Meijdam and Harrie A. A. Verbon, The International Spillover Effects of Pension Reform, September 2005

1541 Richard Disney, Household Saving Rates and the Design of Social Security Programmes: Evidence from a Country Panel, September 2005

1542 David Dorn and Alfonso Sousa-Poza, Early Retirement: Free Choice or Forced Decision?, September 2005 
1543 Clara Graziano and Annalisa Luporini, Ownership Concentration, Monitoring and Optimal Board Structure, September 2005

1544 Panu Poutvaara, Social Security Incentives, Human Capital Investment and Mobility of Labor, September 2005

1545 Kjell Erik Lommerud, Frode Meland and Odd Rune Straume, Can Deunionization Lead to International Outsourcing?, September 2005

1546 Robert Inklaar, Richard Jong-A-Pin and Jakob de Haan, Trade and Business Cycle Synchronization in OECD Countries: A Re-examination, September 2005

1547 Randall K. Filer and Marjorie Honig, Endogenous Pensions and Retirement Behavior, September 2005

1548 M. Hashem Pesaran, Til Schuermann and Bjoern-Jakob Treutler, Global Business Cycles and Credit Risk, September 2005

1549 Ruediger Pethig, Nonlinear Production, Abatement, Pollution and Materials Balance Reconsidered, September 2005

1550 Antonis Adam and Thomas Moutos, Turkish Delight for Some, Cold Turkey for Others?: The Effects of the EU-Turkey Customs Union, September 2005

1551 Peter Birch Sørensen, Dual Income Taxation: Why and how?, September 2005

1552 Kurt R. Brekke, Robert Nuscheler and Odd Rune Straume, Gatekeeping in Health Care, September 2005

1553 Maarten Bosker, Steven Brakman, Harry Garretsen and Marc Schramm, Looking for Multiple Equilibria when Geography Matters: German City Growth and the WWII Shock, September 2005

1554 Paul W. J. de Bijl, Structural Separation and Access in Telecommunications Markets, September 2005

1555 Ueli Grob and Stefan C. Wolter, Demographic Change and Public Education Spending: A Conflict between Young and Old?, October 2005

1556 Alberto Alesina and Guido Tabellini, Why is Fiscal Policy often Procyclical?, October 2005

1557 Piotr Wdowinski, Financial Markets and Economic Growth in Poland: Simulations with an Econometric Model, October 2005

1558 Peter Egger, Mario Larch, Michael Pfaffermayr and Janette Walde, Small Sample Properties of Maximum Likelihood Versus Generalized Method of Moments Based Tests for Spatially Autocorrelated Errors, October 2005 